TITLE:

\title{
Fluorine-doped indium oxide thin films prepared by chemical vapor deposition
}

$\operatorname{AUTHOR}(S):$

MARUYAMA, T; NAKAI, T

\section{CITATION:}

MARUYAMA, T ...[et al]. Fluorine-doped indium oxide thin films prepared by chemical vapor deposition. JOURNAL OF APPLIED PHYSICS 1992, 71(6): 2915-2917

\section{ISSUE DATE:}

1992-03-15

URL:

http://hdl.handle.net/2433/43534

\section{RIGHT:}

Copyright 1992 American Institute of Physics. This article may be downloaded for personal use only. Any other use requires prior permission of the author and the American Institute of Physics. 


\title{
Fluorine-doped indium oxide thin films prepared by chemical
} vapor deposition

\author{
Toshiro Maruyama and Tsuyoshi Nakai \\ Department of Chemical Engineering, Faculty of Engineering, Kyoto University, Kyoto 606, Japan
}

(Received 11 October 1991; accepted for publication 6 December 1991)

\begin{abstract}
Iransparent conductive fluorine-doped indium oxide thin films were prepared by an atmospheric-pressure chemical vapor deposition method. The raw material was $\left[\mathrm{C}_{7} \mathrm{H}_{15} \mathrm{COO}\right]_{2} \mathrm{In}\left[\mathrm{H}\left(\mathrm{CF}_{2}\right)_{4} \mathrm{COO}\right]$. The polycrystalline films were obtained at a reaction temperature in the range of $350-450{ }^{\circ} \mathrm{C}$. This chemical vapor deposition method incorporates fluorine atoms into a crystalline structure and consequently leads to a high carrier concentration, yielding fluorine-doped indium oxide films of low resistivity. For the 320-nmthick film deposited at $380^{\circ} \mathrm{C}$, the resistivity was $4.4 \times 10^{-4} \Omega \mathrm{cm}$, and the sheet resistance was $13.8 \Omega / \square$.
\end{abstract}

\section{INTRODUCTION}

Indium oxide $\left(\operatorname{In}_{2} \mathrm{O}_{3}\right)$ thin films have a wide range of applications, e.g., transparent electrodes of liquid crystal and other displays, with developing preparation methods of thin films of high quality. In particular, $\mathrm{In}_{2} \mathrm{O}_{3}$ films doped with tin (ITO) are widely used as transparent conductive films. Recently, fluorine-doped indium oxide $\left(\mathrm{In}_{2} \mathrm{O}_{3}: \mathrm{F}\right)$ has been reported to have potential applications as a transparent conductive film. ${ }^{1-4}$

High-quality $\operatorname{In}_{2} \mathrm{O}_{3}$ film has been prepared by various physical vapor deposition methods such as vacuum evaporation, if sputtering, dc sputtering, and if ion plating. However, reports on the use of the chemical vapor deposition (CVD) methods ${ }^{4-7}$ are few in spite of the fact that the CVD method does not require a high vacuum and accordingly has the advantage of relative ease for largescale application, granting the possibility of coating complicated shapes. $\mathrm{In}_{2} \mathrm{O}_{3}$ film has been difficult to prepare by the thermal CVD method because of a lack of volatile, thermally stable precursor materials. In addition, the $\mathrm{In}_{2} \mathrm{O}_{3}: \mathrm{F}$ film deposition processes ${ }^{4}$ have suffered from a lack of reproducibility because of the difficulty in doping fluorine.

In this paper, an indium 2-ethylhexanoate derivative is proposed as a precursor material for obtaining $\operatorname{In}_{2} \mathrm{O}_{3}: \mathrm{F}$ films. The low-temperature CVD of this raw material, which involves bonds with fluorine atoms, yields fluorinedoped films with no need of supplying a fluorine donor. ${ }^{8}$ The reaction temperature for obtaining the film of the lowest resistivity will be discussed on the basis of the carrier concentration and mobility which were measured by using the Hall effect.

\section{EXPERIMENT}

Indium 2-ethylhexanoate derivative $\left(\left[\mathrm{C}_{7} \mathrm{H}_{15} \mathrm{COO}\right]_{2}\right.$ $X$ In $\left[\mathrm{H}\left(\mathrm{CF}_{2}\right)_{4} \mathrm{COO}\right]$, Nihon Kagaku Sangyo Co., Ltd.) of reagent grade was used as the source materials. $\left[\mathrm{C}_{7} \mathrm{H}_{15} \mathrm{COO}\right]_{2} \mathrm{In}\left[\mathrm{H}\left(\mathrm{CF}_{2}\right)_{4} \mathrm{COO}\right]$ was placed in a container maintained at $280^{\circ} \mathrm{C}$. The generated gas was entrained by nitrogen carrier gas.
$76 \times 26 \mathrm{~mm}$ borosilicate glass plates and quartz glass plates were used as the substrates. The substrate was placed in the reactor heated by an external electric furnace. The reaction temperature ranged from 350 to $450^{\circ} \mathrm{C}$.

The composition of the film was measured by x-ray photoelectron spectroscopy. The crystallinity of the film was analyzed by the $\mathrm{x}$-ray diffraction method with $\mathrm{Cu} K \alpha$ radiation. The electric resistivity of the film was measured by the van der Pauw method. The optical transmittance of the film was obtained by means of a multipurpose recording spectrophotometer. A blank glass substrate was inserted into the reference beam path of the spectrophotometer.

\section{RESULTS AND DISCUSSION}

The transparent conductive $\mathrm{In}_{2} \mathrm{O}_{3}: \mathrm{F}$ film was obtained by thermal decomposition of $\left[\mathrm{C}_{7} \mathrm{H}_{15} \mathrm{COO}\right]_{2}$ $\times \operatorname{In}\left[\mathrm{H}\left(\mathrm{CF}_{2}\right)_{4} \mathrm{COO}\right]$ in an inert (nitrogen) atmosphere. That is, the thermal decomposition of metallic complex salt, which involves metal -oxygen bonds, yields metal oxide film with no need of supplying an oxygen donor. This reaction scheme is consistent with that observed in the preparation of $\operatorname{In}_{2} \mathrm{O}_{3}$ film from indium carbonate. ${ }^{4,5}$

Figure 1 shows a typical example of the $x$-ray diffraction pattern of the $\mathrm{In}_{2} \mathrm{O}_{3}: \mathrm{F}$ film deposited on a borosilicate glass at $380^{\circ} \mathrm{C}$. The pattern indicates a characteristic large (400) peak. Figure 2 shows the ratio of the intensity of (400) peak to (222) peak as a function of reaction tem-

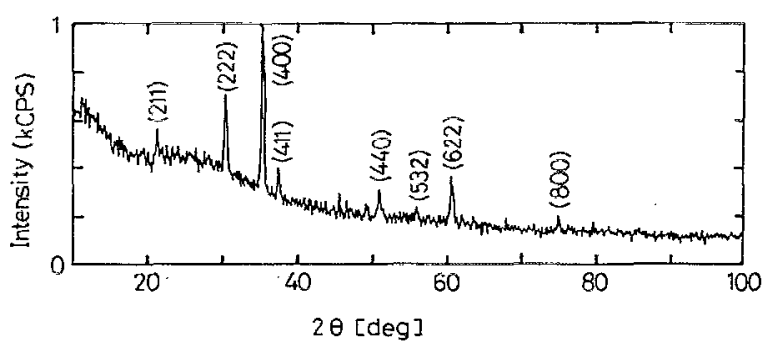

FIG. 1. X-ray diffraction patterns of the $\mathrm{In}_{2} \mathrm{O}_{3}: \mathrm{F}$ film deposited on borosilicate glass substrate at $380^{\circ} \mathrm{C}$. 


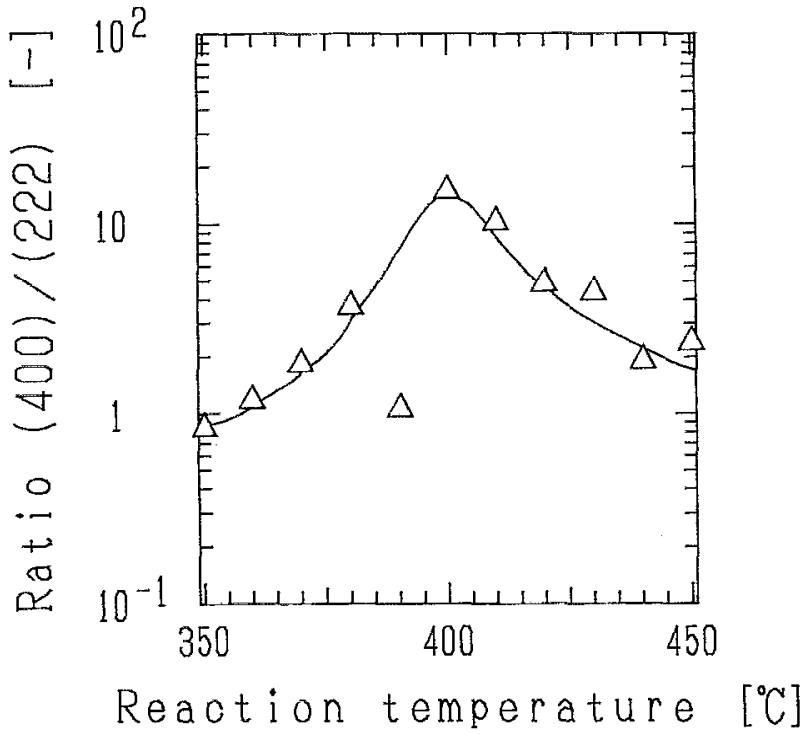

FIG. 2. Ratio of the intensity of (400) peak to (222) peak as a function of reaction temperature.

perature. Within the range of reaction temperature, the ratio is consistently larger than that $(0.33)$ for the nonoriented polycrystalline, indicating (400) plane texturing, which was observed in fluorine doping ${ }^{4}$ and tin doping ${ }^{5,6}$ for $\mathrm{In}_{2} \mathrm{O}_{3}$ film. Figure 3 shows the full width at half maximum (FWHM) of the (400) diffraction peak as a function of reaction temperature. The result suggests that the crystallite size in [400] direction monotonically decreases with increasing reaction temperature. From the value of the FWHM of the (400) diffraction peak, the crystallite size in [400] direction was obtained to be $43 \mathrm{~nm}$ at $400^{\circ} \mathrm{C}$.

Figure 4 shows the electric resistivity, carrier concentration, and Hall mobility for the $\mathrm{In}_{2} \mathrm{O}_{3}: \mathrm{F}$ film as a function

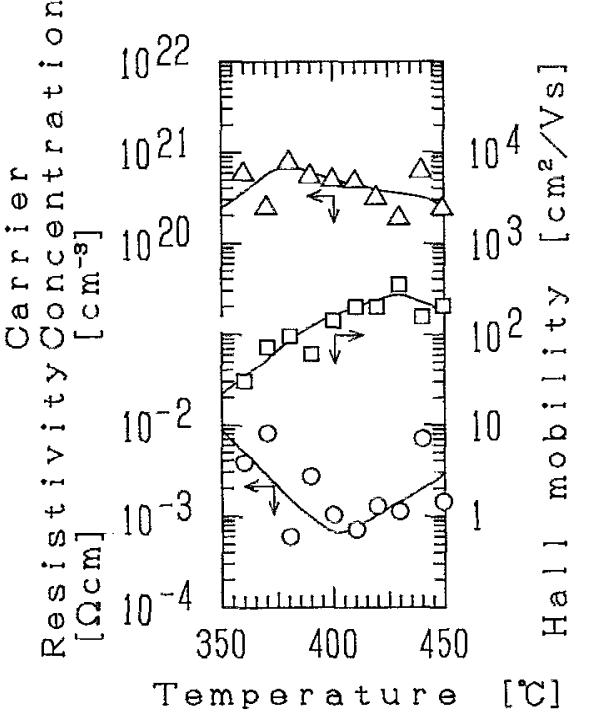

FIG. 4. Electric resistivity, carrier concentration, and Hall mobility for $\mathrm{In}_{2} \mathrm{O}_{3}: \mathrm{F}$ film as a function of reaction temperature.

of reaction temperature. The carrier concentration shows the maximum value at about $370^{\circ} \mathrm{C}$, while the Hall mobility peaks at about $430^{\circ} \mathrm{C}$. As a result, the $\operatorname{In}_{2} \mathrm{O}_{e}: \mathrm{F}$ film give the minimum value of resistivity at $380-400^{\circ} \mathrm{C}$. The lowest resistivity was obtained for the film deposited at $380^{\circ} \mathrm{C}$; the resistivity was $4.4 \times 10^{-4} \Omega \mathrm{cm}$, and the sheet resistance was $13.8 \Omega / \square$ for the 320 -nm-thick film. About the carrier concentration, the fluorine content of the film is expressed as the atomic ratio $\mathrm{F} / \mathrm{In}$, and it is shown in Fig. 5 as a function of the reaction temperature. The fluorine content is maximum at $370^{\circ} \mathrm{C}$, and the content decreases with increasing temperature from $370^{\circ} \mathrm{C}$. A comparison of Fig.

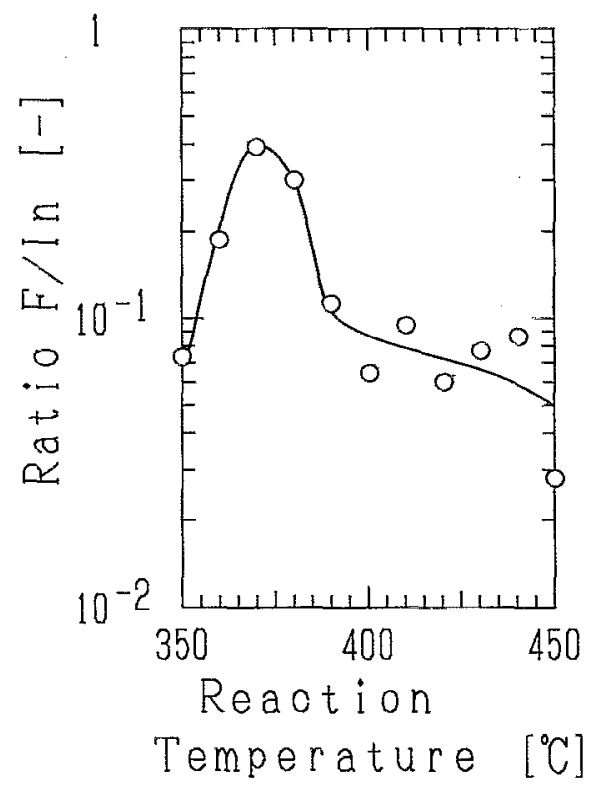

FIG. 5. The ratio $\mathrm{F} / \mathrm{In}$ of $\mathrm{In}_{2} \mathrm{O}_{3}: \mathrm{F}$ film as a function of reaction temperature.
FIG. 3. Full width at half maximum (FWHM) of the diffraction peak corresponding to the $(400)$ reflection as a function of reaction temperature.

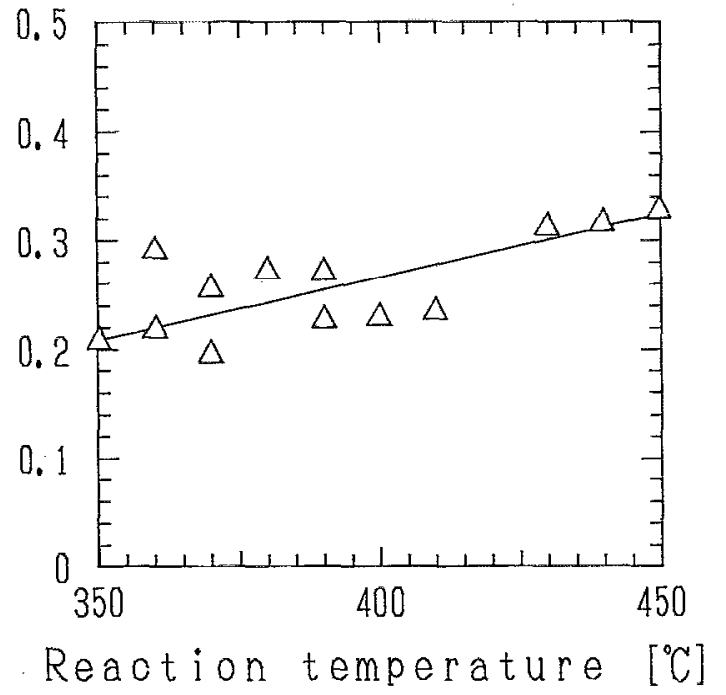




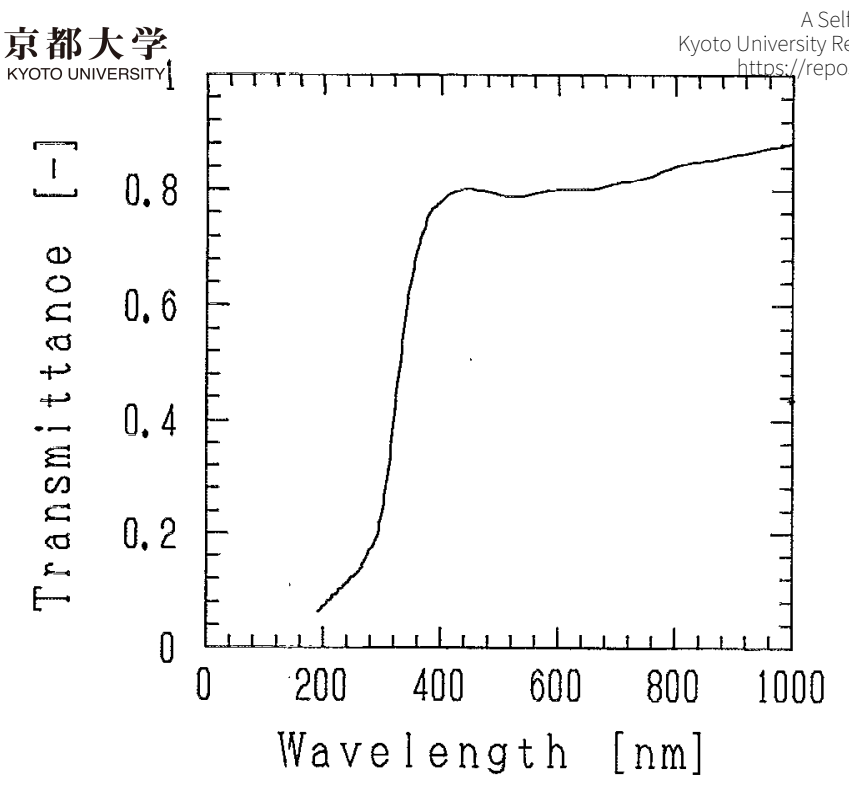

FIG. 6. Optical tran:smittance of $98-\mathrm{nm}$-thick $\operatorname{In}_{2} \mathrm{O}_{3}: \mathrm{F}$ film deposited on quartz glass substrate at $380^{\circ} \mathrm{C}$.

5 and Fig. 4 shows that temperature dependence of fluorine content is similar to that of carrier concentration. However, the fiuorine concentration of the film is higher than that of carrier concentration. For example, at reaction temperature $400^{\circ} \mathrm{C}$ the former is $3.2 \times 10^{21} \mathrm{~cm}^{-3}$ (F/In $=0.1$ ), while the latter is $4.1 \times 10^{20} \mathrm{~cm}^{-3}$. Extra fluorine atoms are inferred to be incorporated into the film as neutral dopants.

Figure 6 shows the optical transmittances for the 98nm-thick film deposited on a quartz glass substrate at $380^{\circ} \mathrm{C}$. The transmittance is more than $80 \%$ in the wavelength range above $400 \mathrm{~nm}$. Figure 7 shows the square absorption coefficients $\alpha^{2}$ as a function of photon energy. The extrapolations to the abscissa indicate that the optical energy gap of $\mathrm{In}_{2} \mathrm{O}_{3}: \mathrm{F}$ for the direct transition is $3.72 \mathrm{eV}$. Thus no deviation from the value for $\operatorname{In}_{2} \mathrm{O}_{3}$ by fluorine doping is observable.

\section{CONCLUSIONS}

Transparent conductive fluorine-doped indium oxide thin films were prepared by an atmospheric-pressure chemical vapor deposition method. The raw material was $\left[\mathrm{C}_{7} \mathrm{H}_{15} \mathrm{COO}\right]_{2} \mathrm{In}\left[\mathrm{I} \mathrm{H}\left(\mathrm{CF}_{2}\right)_{4} \mathrm{COO}\right]$. The polycrystalline films were obtained at a reaction temperature in the range of $350-450^{\circ} \mathrm{C}$. This chemical vapor deposition method incorporates fluorine atoms into a crystalline structure and con-

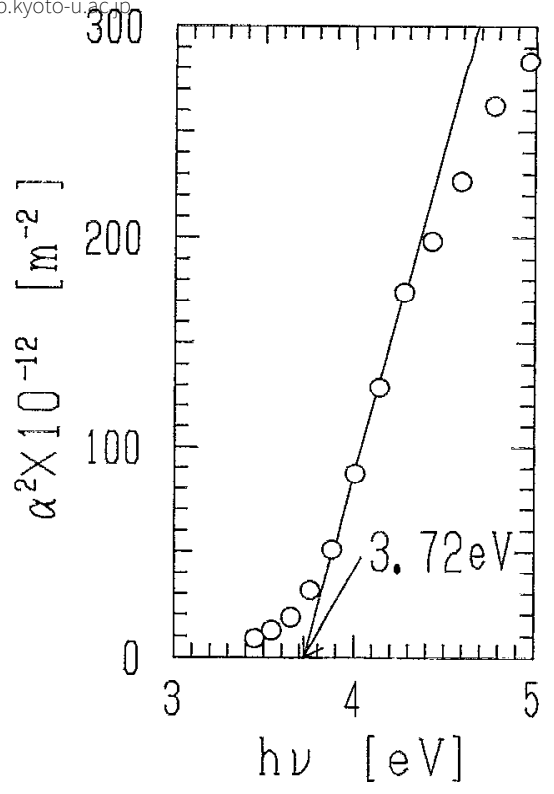

FIG. 7. Square absorption coefficients $\alpha^{2}$ for $\operatorname{In}_{2} \mathrm{O}_{3}: \mathrm{F}$ film as a function of photon energy.

sequently leads to a high carrier concentration, yielding fluorine-doped indium oxide films of low resistivity. For the $320-\mathrm{nm}$-thick film deposited at $380^{\circ} \mathrm{C}$, the resistivity was $4.4 \times 10^{-4} \Omega \mathrm{cm}$, and the sheet resistance was 13.8 $\Omega / \square$.

\section{ACKNOWLEDGMENTS}

This work was supported by the Japan Securities Scholarship Foundation, Nissan Science Foundation, Iketani Science and Technology Foundation, Miyashita Research Foundation for Materials Science, Yazaki Science and Technology Foundation, Nippon Sheet Glass Foundation, and Grant-in-Aid for Scientific Research on Priority Area from the Ministry of Education, Science and Culture. The authors would like to thank $H$. Kawahara and $K$. Nakanishi of the Nippon Sheet Glass Co., Ltd. for the Hall coefficient measurements.

'J. A. Avaritsiotis and R. P. Howson, Thin Solid Films 77, 351 (1981).

${ }^{2}$ J. A. Avaritsiotis and R. P. Howson, Thin Solid Films 80, 63 (1981).

${ }^{3}$ S. P. Singh, L. M. Tiwari, and O. P. Agnihotri, Thin Solid Films 139, 1 (1986).

${ }^{4}$ T. Maruyama and K. Fukui, Jpn. J. Appl. Phys. 29, L1705 (1990).

${ }^{5}$ T. Maruyama and K. Tabata, Jpn. J. Appl. Phys. 29, L355 (1990).

${ }^{6}$ T. Maruyama and K. Fukui, Thin Solid Films 203, 297 (1991).

${ }^{7}$ T. Maruyama and K. Fukui, J. Appl. Phys. 70, 3848 (1991).

${ }^{8}$ T. Maruyama and K. Tabata, J. Appl. Phys. 68, 4282 (1990). 